\title{
The use of indigenous ecological resources for pest control in Africa
}

\author{
D. Grzywacz • P. C. Stevenson • W. L. Mushobozi • \\ S. Belmain • K. Wilson
}

Received: 25 April 2013 / Accepted: 13 November 2013 /Published online: 26 November 2013

(C) The Author(s) 2013. This article is published with open access at Springerlink.com

\begin{abstract}
Reducing the losses from crop pests will help to increase food availability and boost economic growth in subSaharan Africa (SSA). However, the existing crop protection paradigm that relies on synthetic agrochemical pesticides has had only a marginal impact on the productivity of many poor smallholder farmers who constitute a major segment of agriculture in SSA. This is primarily because many of them are not able to afford or access these imported chemicals. A solution to this crop protection problem may be to harness biological resources that are locally available, such as endemic insect natural enemies and indigenous pesticidal plant materials. Two specific examples of this already under development in Africa are the use of the pesticidal plant, Tephrosia vogelii, and the harvesting of the endemic insect baculovirus, Spodoptera exempta nucleopolyhedrovirus (SpexNPV). Both of these can be produced locally and have shown promise in trials as inexpensive and effective tools for pest control in Africa and their use is currently being scaled up and evaluated by African networks of researchers. A focus on these systems illustrates the potential for using locally-available natural resources for improved crop protection in Africa. The consideration of these pesticidal plants and insect natural enemies in
\end{abstract}

D. Grzywacz $(\triangle) \cdot$ P. C. Stevenson · S. Belmain

Natural Resources Institute, Chatham Maritime, University of Greenwich, Kent ME4 4 TB, UK

e-mail: d.grzywacz@gre.ac.uk

P. C. Stevenson

Royal Botanic Gardens, Kew, Surrey TW9 3AB, UK

W. L. Mushobozi

Eco Agri Consultancy Services Ltd, PO Box 15040, Arusha,

Tanzania

K. Wilson

Lancaster Environment Centre, Lancaster University, Lancaster

LA1 4YQ, UK the wider context of natural capital that provide valuable ecosystem services (including pest control), will facilitate greater recognition of their true economic and societal worth. While both of these model systems show promise, there are also very significant challenges to be overcome in developing production, supply and marketing systems that are economically viable and sustainable. The regulatory environment must also evolve to accommodate and facilitate the registration of new products and the establishment of appropriate supply chains that share the benefits of these resources equitably with the local communities from which they are harvested.

Keywords African crop pests · Biological control agents · Botanical insecticides $\cdot$ Ecological resources $\cdot$ Ecosystem services $\cdot$ Pest management

\section{Introduction}

Central to the issue of high levels of poverty in sub-Saharan Africa (SSA) is low agricultural productivity. While in the developing countries of Asia and South America there has been a steady increase in the productivity of agriculture, in SSA yields of staple food grains have remained stubbornly low and have barely improved since the 1960s (World Development Report 2008). In the mid-1980s, South Asia and SSA were on a par in terms of both agricultural production (low) and poverty (high). Since then, cereal yields in South Asia have increased by more than $50 \%$, and poverty has declined by more than $30 \%$; in contrast, there has been virtually no shift in either metric for countries in SSA (World Development Report 2008). Food production has increased in most SSA countries but largely through extension of agriculture, i.e. bringing new areas into cultivation, rather than increasing yields from existing farming (Evenson and Gollin 2003). A limitation of this approach is that 
farming is frequently extended into marginal areas even less suitable for agriculture than existing ones and where production can be even more unreliable due to variable rainfall. This problem is especially acute in the non-irrigated smallholder sector of agriculture, and as these millions of subsistence food producers are a major source of basic food grains for millions of Africa's poorest, it remains at the heart of the issue of uncertain food security and continuing poverty in Africa. The problem of increasing food production in the rain-fed, often semi-arid, agricultural systems of eastern and southern Africa is a multi-factorial interaction between many biotic and abiotic factors. However, important among these is the failure of resource-poor farmers to prevent losses due to pre-and postharvest pests.

The objective of this paper is to explore how indigenous ecological resources could be of value in promoting better pest control by poor farmers in Africa, and we illustrate this by focusing on two model systems currently under development. We will also identify the constraints preventing their wider uptake and use, including the technical, ecological, policy and regulatory barriers that would need to be overcome to facilitate the wider use of indigenous ecological resources. Possible ways to overcome some of these barriers are suggested and the research or policy changes necessary to resolve others identified.

\section{Pest control and African agriculture}

Pests in Africa continue to limit food crop harvests. Studies indicate that losses due to pests overall are in the region of $30 \%$ (Lenne 2000; Oerke and Dehne 2004), but localised losses due to outbreaks of major migratory pests such as locusts and armyworms can be even greater, sometimes resulting in complete crop failure (Rose et al. 2000). While crop pests are a problem in all cropping systems globally, their impact is much greater in sub-Saharan Africa, where poverty, limited knowledge and poor agricultural infrastructure mean that much subsistence farming is conducted without access to effective crop protection knowledge or resources (Lenne 2000; N'juki et al. 2004). While tracking and mobilising resources against outbreaks of migratory pests, such as armyworm and locusts present some technical and logistical challenges, the efficacy of synthetic chemical pesticides is not usually a constraint, as resistance to chemical insecticides is not an issue in these species. Indeed, in Africa the relatively low use of pesticides has, apart from a few horticultural pests of intensively-grown export crops such as Diamondback moth, failed so far to create the major pest resistance problems that have been such a feature of agriculture in Asia (Armes et al. 1996; Shelton 2004). The major factor in determining the high crop losses due to pests, and their continuing impact on food security, is that most poor farmers in SSA do not have access to any effective pest control technology. In a socio-economic study in armyworm-affected areas of Tanzania, it was found that up to $70 \%$ of poor farmers did not have access to pesticides during the armyworm outbreak season (N'juki et al. 2004). It is a characteristic of farming in SSA that pesticide use is much lower than in Europe or Asia (Abate et al. 2000). In the poorest areas, this lack of access is partly due to the inability of many farmers to afford pesticide, but also because the sudden demand for pesticides during major pest outbreaks overwhelms the limited local supply. The constrained capacity of local pesticide dealers in much of SSA is arguably a product of the impoverished nature of agriculture in these areas, which has failed to support the development of an adequate supply chain of agricultural inputs. It is noticeable that in areas of SSA where commercial export agriculture is well developed, such as South Africa and parts of Kenya, farmers have much better access to pest control (Gwynn and Maniania 2010).

The search for alternatives to synthetic pesticides is also stimulated by several other factors, including the desire to avoid the problem of obsolete pesticide stocks. It is estimated that in SSA there are $>50,000$ tonnes of obsolete or out of date chemical pesticide stocks (World Bank 2013). Few SSA countries have safe disposal facilities and it has been estimated that to identify, collect, transport and dispose of these pesticides safely will cost US $\$ 1.25$ billion; money that SSA can ill afford. In many cases, the pesticides were originally donated to African countries by development donors/agencies to help them deal with major outbreak pests such as locusts or African armyworm (Crop Life International 2012).

Chemical pesticides are not the only approach to improved pest control: genetic modification (GM), by greatly enhancing plant resistance to pests through incorporation of insecticidal genes, can also be highly effective and has revolutionised the growing of crops such as cotton in Asia (Romeis et al. 2008). However, so far, GM crops have had little impact in SSA due to a number of factors, including the well-publicised public resistance to the growing of GM crops in many countries. Even where they are grown in SSA, GM crop varieties are not always a stand-alone solution to pest losses or a key to increased productivity, as technical effectiveness may not translate into sustained financial impact under the climatic and institutional uncertainties of rain-fed agriculture in SSA (Hofs et al. 2006). Another issue may be the lack of availability of appropriately-transformed local crops and varieties, suited to the diverse rain-fed cropping systems of the resource-poor in SSA. The highly diverse nature of local varieties of staple crops in Africa may require the production and commercialisation of GM varieties specifically adapted to the diverse African systems. However, this may be too costly or technically difficult for local seed companies, and financially unattractive to multinationals due to the fragmented nature of seed markets in SSA and the low value of crops 
grown by poor farmers. Thus, for many of the poorest, GM is not likely to provide a solution to their problems in the foreseeable future.

In the face of this continuing failure to control pest losses in SSA with synthetic chemical insecticides, and no GM solutions, we propose that there is a need to explore more vigorously alternative, more affordable, appropriate and sustainable solutions to the current pest control model that focuses exclusively on the use of imported synthetic chemicals as the primary option. This would not seek to replace current pest control systems where these are effective, nor impede attempts to develop or disseminate modern pest control to a wider constituency, but it could have a useful role in providing an alternative, cheaper, locally-accessible option for the poorest subsistence farmers who cannot afford the more expensive synthetic pesticides or lack the resources to use them. To this end, one alternative approach currently being explored and evaluated in SSA is the use of locally-available ecological resources that could provide sustainable and cheap pest control. Here, following convention (Ehlers 2011; Copping 2009), we refer to these pesticidal ecological resources as biological control agents (BCA) and include within this broad definition insect predators and parasitoids that hunt down and attack their prey (such as parasitic wasps and entomophagous beetles), entomopathogens that infect and parasitize their hosts (including bacteria, fungi and baculoviruses), botanical pesticides that may poison the pest or make the crop unpalatable to them (e.g. pyrethrum and neem products; Isman 2006), as well as plants that indirectly regulate pest populations via semiochemicals (e.g. napier grass and Desmodium; Khan et al. 2010), and other natural products (Copping 2009).

Poor pest control in both preharvest and postharvest situations contributes significantly to food insecurity among poor farmers in sub-Saharan Africa (Lenne 2000). While synthetic chemical insecticides are effective, high cost limits their availability to poor farmers (N'juki et al. 2004; Nyirenda 2013). Increasing the availability and use of low-cost indigenous resources for pest control is an important mechanism that would enable farmers to reduce most readily losses to pests with consequent improvement to food security across Africa where local subsistence farming is a major source of food for urban and rural populations.

\section{Pest control ecosystem services}

An ecosystem service (ES) is "an activity or function of an ecosystem that provides benefit (or occasionally disbenefit) to humans" (Millennium Ecosystem Assessment 2005; Mace et al. 2012). Within this context, biological control agents, as defined above, may be considered as crop pest control service providers or, following the definition of Mace et al. (2012), they are "final ecosystem services" that directly or indirectly (e.g. following simple formulation) provide the "goods" for crop protection. Parasitoids and predators of crop pests have long been viewed in the broader context of the ecosystem to which they belong and, in developed and some developing countries, habitats are specifically managed to facilitate the population growth and survival of the insects that provide this important ecosystem service (Bianchi et al. 2006). However, the same has generally not been the case for other BCA, such as microbial diseases of insects, or for the indigenous plants that are harvested for pest control (but see below). Thus, we argue here that a greater appreciation of BCA may be gained by considering these natural resources as part of the wider ecosystem that provides the goods and services required for human wellbeing. Specifically, by viewing biocontrol agents within a broader ES framework, the following issues are highlighted: (i) BCA are natural resources that should be valued and potentially managed; (ii) over-exploitation of these natural resources may lead to detrimental environmental effects due to inherent trade-offs with other ecosystem services, such as carbon sequestration, crop pollination and water purification; (iii) synthetic chemicals also impact on human and ecosystem health, and hence their use should be placed within the same ES context; and (iv) by acknowledging their role in the wider ecosystem, the true 'value' of BCA is recognised and this should feed into the regulatory and policy frameworks for pesticides in a more appropriate way. The perceived value of the ES approach within this context is illustrated by a $£ 40.5 \mathrm{M}$ programme of research currently funded by the UK research councils and Department for International Development (DFID), which seeks to identify how ecosystem services might be better harnessed to alleviate poverty in developing countries (Anon 2012).

Of course, integrated pest management has long sought to maximise the impacts of BCA through cultivation practices that increase natural enemy biodiversity and some plants, such as pyrethrum and neem, are cultivated in some countries specifically for pest control. However, the concept of harvesting BCA produced in natural ecosystems is, as yet, an underutilised approach. The use of wild plants for pest control in Africa has long been an aspect of traditional knowledge and farming (Belmain and Stevenson 2001; Stoll 2000), but the attempt to scale up the use and exploitation of wild insecticidal plants, and basing it firmly on objective scientific evidence of their chemistry and efficacy, is a more recent development now being implemented in a number of SSA countries (ACP Secretariat 2010). In this paper, two case studies of biocontrol agents produced as ecological services that are under development as pest control solutions for Africa will be examined; these are the use of indigenous pesticidal plants and the African armyworm nucleopolyhedrovirus (SpexNPV). It should be noted that whilst the discussion below specifically applies to locally-available plants and microbes that can be harvested for their pesticidal properties, many of the same 
general principles also apply to other ecological resources that can be harnessed as agricultural inputs.

\section{Biological control agents as alternatives to synthetic chemicals}

In mainstream agriculture, alternatives to synthetic chemicals have, since the 1950s, generally been seen as niche solutions for organic or glasshouse crop agriculture. However, rising concern over the adverse effects of synthetic chemical insecticides and recent EU legislation, have triggered a renaissance of interest in biological control agents in the last decade, as seen both by the growth of this sector (Thakore 2006) and the much increased range of products now available worldwide (Lacey et al. 2001; Copping 2009; Bailey et al. 2010a). European Commission Directives on pesticide registration and usage, and the imposition of maximum residue limits on produce sold in the EU, effectively ban from agricultural use a whole range of pesticides, resulting in an estimated reduction in the number of active pest control chemicals by more than $50 \%$, from over 900 in 1998 to fewer than 400 a decade later (Bielza et al. 2008). This will create major new opportunities for alternatives, such as BCA, which will impact not only on European farming but also globally, as all produce destined for the EU will need to comply with these regulations. For example, dimethoate was banned from all use in Kenya in 2012. The rationale for expanding the role of BCA lies in their combination of compatibility with integrated pest management (IPM), the absence of environmentally-damaging chemicals or crop residues and, for live agents, the ability to multiply and spread spatially and temporally to enhance the impact and sustainability of pest control. However, expanding the production and adoption of BCA in Africa has been slow despite a substantive body of research on the use of BCA for migratory and crop pest control in Africa (Neuenschwander et al. 2003; Cherry and Gwynn 2007). One product, Green Muscle ${ }^{\circledR}$ fungus, was developed by the LUBILOSA programme for locust and grasshopper control (Douthwaite et al. 2001), and several more biopesticides for use against other crop pests have been registered recently in Kenya (Clark et al. 2011), South Africa (Moore 2002) and Ghana (Biocontrol Africa 2012), but large-scale use of BCA for pest control, especially by poor farmers, has not occurred. Here, a major issue is the relatively high cost of some BCA, like Green Muscle, since they are produced in specially-constructed facilities or factories. Arguably, only if $\mathrm{BCA}$ can be produced at a cost lower than existing synthetic insecticides are they likely to be adopted by the large numbers of poor farmers in Africa, due to their relatively slow action compared to chemical pesticides.

Even where chemical pesticides are used in Africa, many farmers do not have sufficient knowledge to ensure their own, or the consumers', safety. With BCA, safety is generally less of an issue due to their much lower toxicity, but adequate knowledge of the BCA target spectrum and their limitations is still needed if they are to be employed effectively. Indeed, given the slower action of BCA, correct application, targeting and timing are even more important (Lisansky 1997). Thus, any attempt to promote BCA to farmers is going to depend upon adequate knowledge dissemination if it is to be effective.

\section{Case study 1: Plant-based pesticides}

Many plant species have pesticidal properties and some offer an effective alternative to synthetic chemicals for pest management by poor farmers in SSA (Belmain and Stevenson 2001). The promotion of these 'botanicals', particularly with optimised applications based on a knowledge of the active plant chemicals (Stevenson et al. 2009), would greatly benefit such resource poor farmers (Dubey 2011). These pesticidal plants are used as crude materials that are harvested locally from wild or human-influenced locations and require only limited processing that is feasible and economically-viable for most farmers. This is in contrast to commercially-produced botanical insecticides, such as pyrethrum or neem products, which are formulated and have undergone relatively sophisticated preparation that is targeted at larger commercialised crop and horticultural production. The familiarity farmers have with these plant materials as pesticides is critical in facilitating their engagement in scaling-up the use of pesticidal plants (Nyirenda et al. 2011). Farmers recognise pesticidal plants as being less toxic to themselves and the environment and accessible at a lower cost than synthetic pesticides (Deng et al. 2009). Pesticidal plants, if produced or harvested by the farmers themselves, also avoid the problem of pesticide adulteration along the supply chain, which is a common problem in SSA (Dinham 2003). Perhaps the most important factor is that their cost to farmers is calculated in terms of time, a resource they often have, rather than cash or credit, of which they have less. Despite these positive attributes, the priority of pesticidal plants in national agricultural policies of most SSA countries remains low (Belmain and Stevenson 2001). Thus, even though interest in plant materials as pesticides by SSA farmers is high, relatively few actually use plant materials (Kamanula et al. 2011). One reason for this is because their use is not actively promoted by governments, despite international financial support for organic farming in some SSA countries (e.g. Kasisi Agricultural Training Centre, Zambia; Kenyan Institute of Organic Farming). Governments do promote the commercial growing of some pesticidal plants, as occurs with the commercial-scale growing of pyrethrum, Tanacetum cinerariifolium, in East Africa. Nonetheless, as pyrethrum is grown as an export cash crop, few Kenyan farmers actually 
use it for pest control on their own crops. The lack of support by SSA governments may be due to gaps in knowledge or because current policy and regulatory frameworks are inadequate or too restrictive to permit or encourage their large-scale use or commercialisation.

\section{Efficacy of pesticidal plants}

Comprehensive lists of African pesticidal and deterrent species are available (e.g., Stoll 2000) that provide potential solutions against many major agricultural pests in SSA using low-technology preparations and application methods. It should be noted that many plant species reported to be effective for pest control still require scientific validation in the field because of the inherent geographical and seasonal variability in biological activity in some plant species. Analytical chemistry is required in the selection of elite plant materials being chosen for propagation or cultivation to ensure that they are effective (Stevenson et al. 2012; Sarasan et al. 2011). One good example of a cultivated multi-use species with pesticidal properties is Tephrosia vogelii Hook f., which has been used across Africa as a pesticide, as animal fodder and for improving soil fertility (Burkill 1995; Mafongoya and Kuntashula 2005; Neuwinger 2004; Kamanula et al. 2011: Fig. 1). The positive potential impact on poor farmers' livelihoods in SSA of this multi-use plant is compelling, and it is now widely

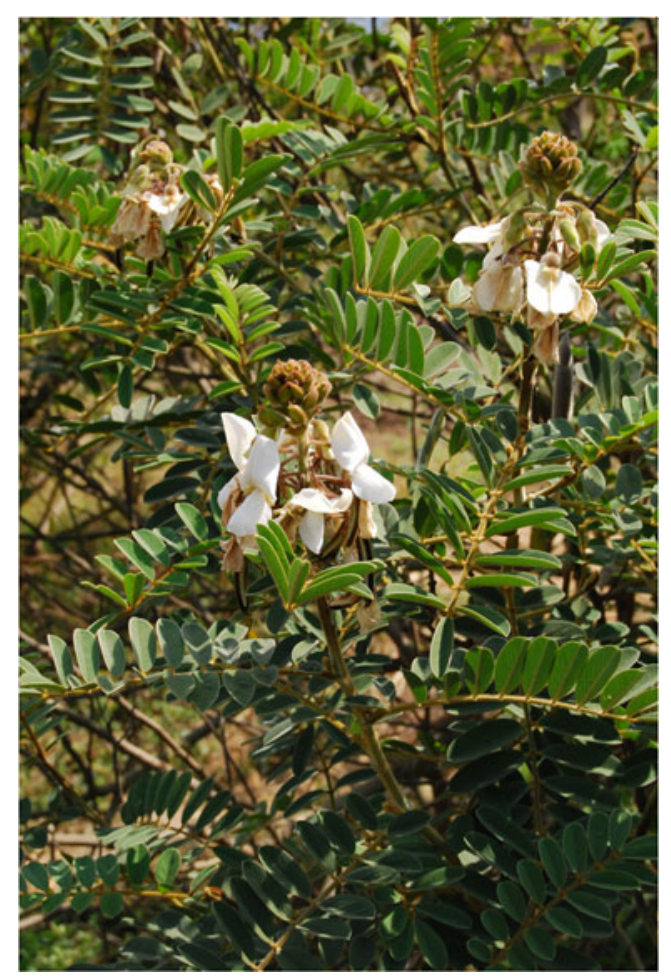

Fig. 1 Tephrosia vogelii, a pesticidal plant widely used for pest control in Malawi (P.C. Stevenson) cultivated in southern and eastern Africa, providing additional ecosystem services beyond pest control. It is especially popular among farmers in Malawi, where $70 \%$ of farmers in published surveys report its application for pest control (Kamanula et al. 2011; Nyirenda et al. 2011: Fig. 2). Growing T. vogelii enables farmers to cultivate their own pesticidal material rather than spend time harvesting it from the wild, a practise that may have negative ecosystem impacts. However, the promotion of existing plant materials may be flawed as some of the plant material distributed is a chemotype that contains none of the insecticidal rotenoids responsible for the pesticidal activity (Stevenson et al. 2012). A survey reported by Stevenson et al. (2012) in northern Malawi suggests that the ineffective chemotype comprises $25 \%$ of the Tephrosia growing on farms. Whilst Tephrosia was mainly promoted for its soil-enriching properties, its pesticidal efficacy was assumed but not validated. Thus, 1 in 4 farmers who use T. vogelii for pest control may find it is ineffective and risk losing their field crops or stored grain if they rely on it. This emphasises the importance of chemical analysis and quality control in validating material before promotion and identifies a flaw in their wide-scale value - the inherent variability in plant chemical composition. However, good management of resources and careful selection for cultivation can overcome this problem.

Harvesting and propagation

For many pesticidal species there is insufficient knowledge about their propagation to make large-scale cultivation feasible. The use of wild plants is sustainable where they are abundant or where the number of farmers using them matches the capacity of the ecosystem to replenish stocks. However, there are already examples where the demand for medicinal plants has outstripped supply (Shackleton et al. 2005;

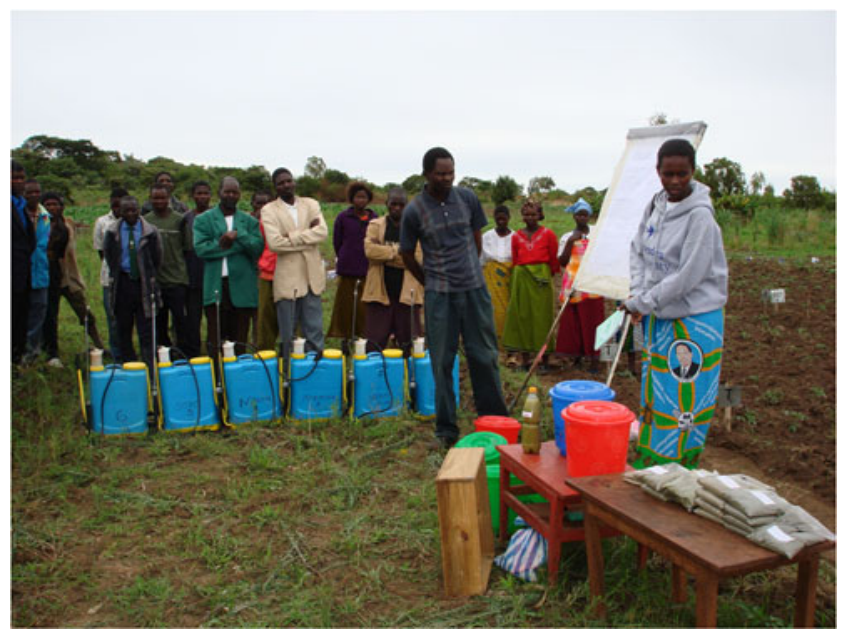

Fig. 2 A farmer awareness day in Malawi; lead farmers demonstrate the use of pesticidal plants (P.C. Stevenson) 
Harnischfeger 2000). Moreover, a lack of knowledge about the chemistry of some species means that it is not possible to currently identify optimal strategies for harvesting some of these species (Sarasan et al. 2011). Thus, if such wild plants are to meet probable demand, then significant additional research on their management, appropriate harvesting systems and determining sustainable exploitation pressure still needs to be carried out. In other words, these pesticidal plants need to be viewed as exploitable service providers within the wider ecosystem.

Efforts to optimize the propagation of pesticidal plants that cannot be easily cultivated, and have only limited availability in the wild, are required for some species. Recent progress in propagation has been made with several pesticidal trees including snake bean, Bobgunnia madagascariensis and violet tree, Securidaca longepedunculata (Zulu et al. 2011 and Thokozani et al. 2011). In the case of B. madagascariensis, most parts of the plant have been reportedly used for pest control, but the pods are of particular interest due to their reported efficacy as insecticides and molluscicides (Burkill 1995). However, variation in the compounds associated with its biological activity are known to occur in pods from different geographic locations, and this needs to be monitored to ensure that only elite materials are promoted or propagated (Sarasan et al. 2011). Home cultivation of plants reduces harvesting pressure on degraded habitats, and increasing the scale of home-grown planting of pesticidal plants may lead to entrepreneurial opportunities for income-generation by growers. Harvesting plants from natural woodlands can cost considerable time, which makes using some species less attractive to farmers; hence, it may be better to commercialise the harvesting, propagation, preliminary processing and distribution. These activities would arguably be best carried out by small businesses driven by commercial incentives rather than depending upon the government extension sector and NGO initiatives. Commercialisation may also lead to increased uptake by farmers, particularly among younger farmers who perceive that purchased packaged products are more effective, and the more educated who often cast aside traditional knowledge (Deng et al. 2009). Hence, the propagation and marketing of pesticidal plants reduces pressure on wild resources, provides farmers with sustainable sources of the more sought-after, more effective plant species and opens the market to a younger more educated generation of farmers. In Kenya, there is a constitutional requirement that $10 \%$ of land should be planted with trees, and public organizations such as schools are mandated to move towards self-sustainability in natural resources such as wood. However, much of this planting is being enacted with exotic species such as Eucalyptus. The identification of local pesticidal or medicinal trees offers greater potential biodiversity and added value to these afforestation programmes that may additionally provide opportunities to contribute profitably to the Kenyan government.
Preparation and application

How the plant is prepared and applied is also an issue. $S$. longepedunculata is reported to have numerous uses and it is known that the root bark is insecticidal to stored grain beetles (Jayasekera et al. 2005; Belmain and Stevenson 2001). This activity has been validated and was attributed to methylsalicylate, which is abundant in the roots (Jayasekera, et al. 2002), and saponins, which are specific to the roots (Stevenson et al. 2009). Field trials indicate that the stem bark lacks efficacy in storage pest management whereas the root bark is effective (Stevenson et al. 2010). Thus, the pest control activity that is restricted to the root bark can be explained by the differing chemistries between the two parts of the plant. Recent analyses indicate that the plant population across Africa from Ghana to Zambia has chemical homogeneity (Sarasan et al. 2011), but because the root is used, this requires sustainable harvesting practises. For example, in northern Ghana, farmers harvest lateral roots and replace the soil to allow the tree to continue growing in situ. Since only root bark of $S$. longepedunculata is effective, ways to reduce the amount of root required would be one step towards more sustainable use. For example, water extracts of the bark remove the biologically active saponins and this extract can be used to treat grain uniformly prior to storage rather than using crudely pounded plant material. Recent field trials, however, indicate that this approach is not popular with farmers owing to the complexity and labour-intensive extraction and subsequent application, even though the practice required half as much plant material to treat the same amount of commodity (P.C. Stevenson, unpublished).

The effective use of any pesticide requires knowledge to ensure that materials are applied optimally and this is just as true for plant extracts as for other pesticides. Small plots of just a few hectares are common in SSA and such resourcepoor growers may apply pesticides in a watering can, or using a broom and bucket, rather than a knapsack sprayer, exacerbating problems with variable, uneven application. Also, most farmers make extracts of pesticidal plant materials in cold water, yet the biologically-active chemicals in plants are often highly non-polar meaning cold water is an inefficient extraction medium. The use of hot water or adding soap during extraction enhances active component extraction (Belmain et al. 2012). Soaps also optimise the effectiveness of the plant extracts acting as surfactants, improving the spreading and sticking of active components (Ssenyonjo and Kyaterekera 2009). Chemical analysis and determination of the components that confer activity would help in establishing the best uses and optimal application rates of plant materials for different crops and/or pest species.

Historically, plants have contributed to traditional pest management practice by SSA farmers and, we argue, that 
pesticidal plants remain a significant but under-exploited pest management option for small-scale farmers who are unable or unwilling to use synthetic insecticides due to their cost, safety or availability. To ensure their future role in SSA agriculture, the hurdles to their greater uptake and commercialisation need to be identified and addressed by scientists, regulators and policy makers. Ultimately, the goal of pesticidal plant research in Africa should be to develop simple, safe and environmentally conscientious protocols for exploitation, regulation and use that can be easily understood and distributed widely by extension services and NGOs.

\section{Case study 2: African armyworm baculovirus}

The African armyworm (Spodoptera exempta) is a major migratory insect pest that is a perennial threat to food production over much of eastern and southern Africa (Fig. 3). This pest has a well understood migratory cycle with outbreaks originating each year in well-identified primary outbreak areas of Tanzania and Kenya before moving out across Africa. Armyworm outbreaks are characterised by the sudden appearance of dense aggregations of caterpillars (commonly 100 larvae per $\mathrm{m}^{2}$, but occasionally in excess of 1,000 per $\mathrm{m}^{2}$ ) over areas of many hectares (Scott 1991; Rose et al. 2000). Larvae within these high-density outbreaks typically graze down all the local grasses and graminaceous crops such as maize, rice, sorghum, barley and wheat (Scott 1991; Rose et al. 2000). Egg-laying is usually co-ordinated with the onset of local rains, so armyworm outbreaks coincide with the germination of new crops. In semi-arid areas of SSA, where the crop-producing rainy periods occur only once or twice a year, outbreaks can be especially devastating, as the replanted crop may not mature before the rains have ended. After completing the larval cycle, armyworms burrow into the ground and pupate. The subsequent mass emergence of adults

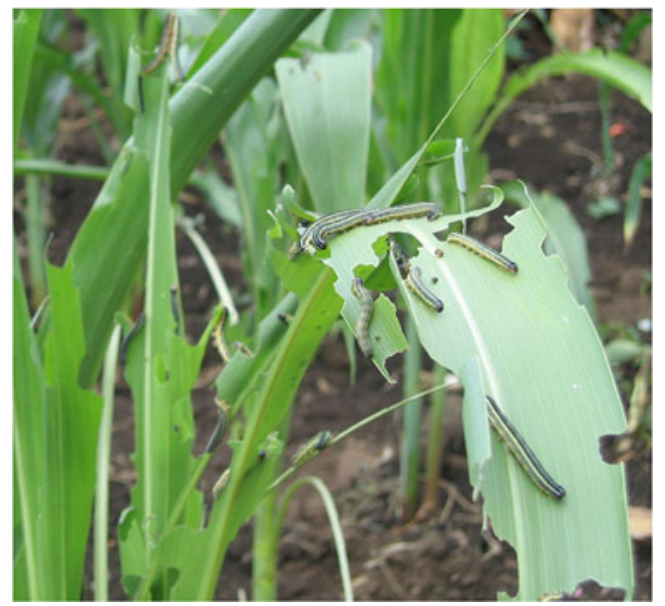

Fig. 3 African armyworms feeding on young maize plant (K. Wilson) then produces nocturnal swarms of moths that follow the rainbearing winds to new areas where fresh grasses and crops may be starting to grow. In this way, outbreaks can go through a series of 5-7 generations for periods of up to eight months, moving across Africa from coastal regions of Tanzania/ Kenya, spreading through these countries north to Ethiopia and the Arabian Peninsula and/or south towards Malawi and South Africa (Rose et al. 2000). Depending on local and seasonal conditions, outbreaks may fade in severity over time or expand to major plague proportions. In 2007/08, severe armyworm outbreaks in Ethiopia affected $>279,000$ hectares of cropland (USAID 2008) in a country already struggling to feed its population. Outbreaks of a similar scale occurred in southern Africa in 2012/13, when in Zambia alone armyworm were reported in seven of the country's ten provinces and $>96$, 000 hectares of maize and pasture were infested, affecting close to 73,000 farmers (USAID 2013). Widespread loss of grazing can also have significant impact on the livelihood of pastoralists.

SpexNPV (Spodoptera exempta nucleopolyhedrovirus) is a natural pathogen of the African armyworm and is a member of the baculoviruses (BV), a group specific to invertebrates that have been developed as biological pesticides for a number of lepidopteran species (Moscardi 1999; Lacey et al. 2001: Fig. 4). A major review of over 50 years of $\mathrm{BV}$ use has judged them to be safe for pest control (O.E.C.D 2002). Indeed, many BVs such as SpexNPV are so specific that they infect only a single, or a few closely related, host species (Cherry 1992). SpexNPV was first identified as a potential BCA in the 1960s when research determined that it was an important factor in the collapse of some armyworm outbreaks (Brown and Swaine 1965). However, this research also indicated that SpexNPV tended to appear only late in the seasonal cycle of armyworm outbreaks, and in most years it failed to prevent serious outbreaks and crop losses (Odindo 1983). While there was some interest in

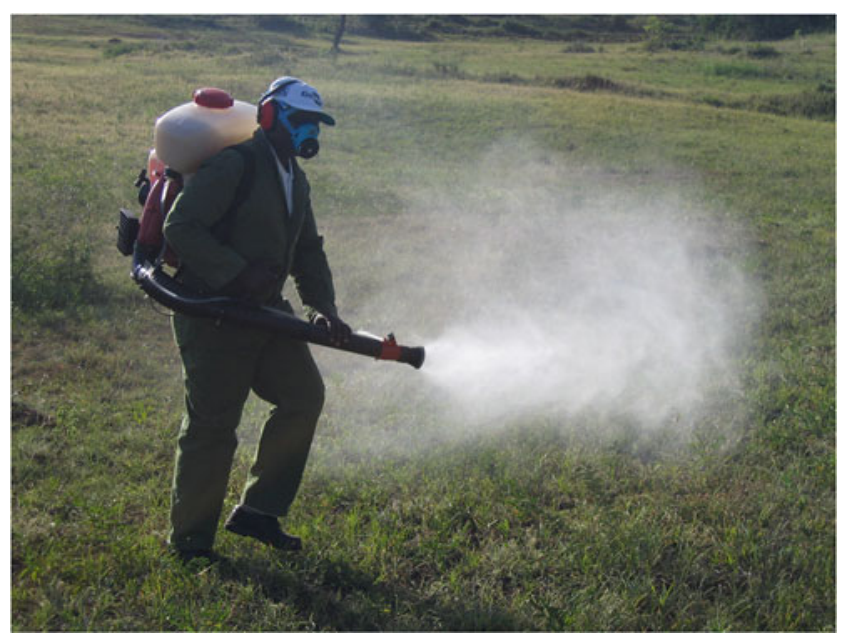

Fig. 4 Spraying Spodoptera exempta nucleopolyhedrovirus for armyworm control in Tanzania (W. Mushobozi) 
developing SpexNPV as a biocontrol agent for armyworm (Odindo 1981), as long as cheap chemical pesticides were available, and acceptable to control organisations and aid donors, little real progress was made in developing SpexNPV as a practical alternative to chemical pesticides. It was in the early 1990s that interest in biological control for armyworm reemerged, as rising environmental concerns made large-scale application of broad-spectrum chemical insecticides less acceptable. More specific products, such as Acylurea insecticides and biological pesticides including Bacillus thuringiensis, were tested and found to be effective in controlling armyworm (Fisk et al. 1993; Broza et al. 1999), though the cost of these as imported from Europe or USA was still too high for most African users. Neem trees are widespread in some armyworm outbreak areas and neem extracts are, therefore, of potential use to some resource-poor farmers (Tanzubil and McCaffery 1990; Grzywacz et al. 2008). Research also focussed on SpexNPV host range (Cherry 1992), the dynamics of virus replication in African armyworm (Cherry et al. 1997) and the ecology of the natural host-pathogen interaction (Graham et al. 2012).

A collaborative programme in Tanzania investigated biological control of African armyworm with SpexNPV, and a series of field trials showed that this could perform as well as chemical pesticides in suppressing armyworm outbreaks if applied early enough when larvae were young (Grzywacz et al. 2008). One significant issue for SpexNPV, as for many other BCAs, is that they are not as rapidly acting as chemical pesticides, commonly taking 3-7 days to kill (Cherry et al. 1997; Grzywacz et al. 2008). They also do not work as well on late-instar caterpillars, which are much more resistant to BVs than early instars (Odindo 1981; Cherry et al. 1997). Thus, effective forecasting and early location of armyworm outbreaks, followed by prompt application, remains a crucial prerequisite of any successful SpexNPV-based control (Day et al. 1996; Mushobozi et al. 2005; Holt et al. 2006).

A great advantage of SpexNPV, as with other BVs, comes from it being an 'occluded' virus. This means that its infective virus particles come naturally encapsulated in a stable protein crystal matrix that gives it good persistence and robustness, with potentially a long shelf-life (Smit 1997). Another advantageous property of BVs is their systemic infectivity; a wide range of host tissues are infected. This makes for a faster host kill and, very importantly, massive multiplication of virus in infected insects. A dead SpexNPV-killed armyworm may contain 200 million infective occlusion bodies (OB), each of which harbours $>100$ infective virions, and a dead larva may comprise $>15 \%$ dry weight of OB (Cherry et al. 1997: Fig. 5). This makes producing SpexNPV in live larvae very efficient and means that insects killed by virus release massive numbers of $\mathrm{OB}$ into the environment on death, helping to spread the infection and promote its persistence. This property of SpexNPV to multiply in infected insects, and then to generate new infections ('secondary cycling'), gives it a means of

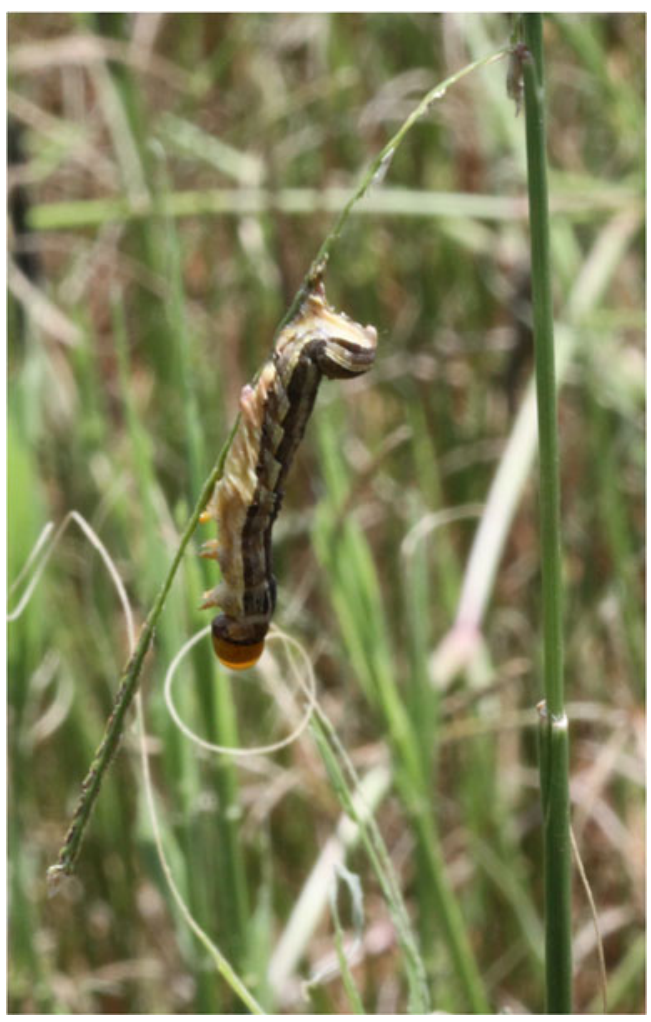

Fig. 5 African armyworm killed by Spodoptera exempta nucleopolyhedrovirus showing discharge from head containing infectious occlusion bodies (K. Wilson)

persisting well beyond the immediate lifespan of the virus when applied, which is useful as most BCA are much less environmentally-robust than chemical pesticides. Thus, through the impact of direct infections and secondary cycling, BCA such as SpexNPV can be just as effective as conventional pesticides, albeit slower to kill (Grzywacz et al. 2008).

\section{Production of SpexNPV for poor farmers}

While there is anecdotal information suggesting that some farmers may harvest virus-infected insects to control armyworms on crops by mixing with water and spraying the filtered solution (K. Wilson, pers. obs.), this "homemade" approach is not seen as a sustainable or reliable strategy for SpexNPV use (Rose et al. 2000; Grzywacz et al. 2009). However, SpexNPV could be a strong candidate as a BCA for large-scale use if produced commercially, despite very significant constraints to its adoption. Some of these relate to technical issues about scaling-up of production, while others relate more to generic issues of how BCA can be developed into commercial products that can be produced and traded in Africa. Cherry and Gwynn (2007) identified a raft of issues concerning how BCA are registered, regulated and promoted that can act as impediments to getting BCA products to the marketplace. 
However effective a crop protection technology is, targeting resource-poor farmers in Africa has to factor in the inability of farmers to afford expensive inputs. Many farmers cannot afford even the cheapest synthetic pesticides so if a new BCA, such as SpexNPV, is to benefit the poor then low cost must be a key priority. Currently, most BV products are globally mass-produced in bespoke facilities using speciallyreared insects, a technique that makes it hard to produce them more cheaply than generic chemical insecticides (Jenkins and Grzywacz 2000). The key issue is whether this BCA can be produced more cheaply than imported chemical pesticides. The mainstream approach to producing biopesticides is to grow them in custom-built production facilities, such as fermenters (nematodes, fungi or bacteria) or in vivo in large numbers of live insects reared in specialist facilities (some bacteria, all viruses and protozoa), which means they often cost more than simple synthetic chemicals (Smit 1997). Production in developing countries, with their cheap labour, can ameliorate this cost issue but rarely eliminate it entirely.

A striking exception to this higher cost is seen in the case of the Brazilian biopesticide, Anticarsia gemmatalis NPV, AgNPV (Moscardi 1999). Here, virus production is carried out not in capital-intensive production laboratories, but in the wild using living insects naturally feeding on plants. Locally, high-density natural infestations of the host insect, the velvet bean caterpillar, A. gemmatalis, are identified then inoculated by spraying with AgNPV. The virus is allowed to multiply in these wild insects and then the virus-killed insects are harvested by hand-collection for later processing into new biopesticide. Simple maceration of the virus-filled cadavers releases the virus, which is then filtered and formulated with a clay carrier before drying to produce a simple but stable biopesticide product (Moscardi 1999). Using this approach, AgNPV can be produced at costs much lower than conventional pesticide and production of $>20$ tonnes of infected insects provides enough to treat $1,000,000$ ha in Brazil annually (Moscardi 2007). This approach has also been adapted for the production of BV of forest pests in India (Sajeev et al. 2005). Given the high-density outbreaks seen in African armyworm, which often occur on low-value pastureland, a similar approach would seem a potentially feasible way to produce low-cost SpexNPV for Africa. Because field production does not incur the capital overheads associated with rearing massive numbers of live insects, and harvesting is done by cheap unskilled labour, AgNPV can be produced in Brazil at a cost of just $\$ 1.26$ per hectare (Moscardi 2007), compared to $>\$ 10$ per hectare for factory-produced chemicals and baculoviruses. Pilot studies in Tanzania have shown that SpexNPV can be successfully harvested from wild armyworm outbreaks and formulated as an air-dried product (Mushobozi et al. 2005). However, it remains a challenge to determine if this production can be scaled-up for SpexNPV as successfully as it has in Brazil for AgNPV.
A separate technical issue in promoting BCA to poor farmers is the need for stable products with good ambient shelf-life. Many first-generation baculovirus products in Asia were produced as aqueous or liquid suspensions requiring cool storage (Jenkins and Grzywacz 2000). This is not a critical problem in the intensive periurban horticulture systems of Kenya or South Africa, but it is certainly a problem in most of SSA and the poor farmers most at risk from armyworm who generally lack access to refrigerators for storing BCA. The AgNPV product is a cheap, air-dried kaolin-formulated biopesticide with good long-term storage properties (Medungno et al. 1997). It has long been recognised that BCA should have a shelf-life of at least 2 years and preferably 4 years (Burges and Jones 1998) and, given the episodic outbreak pattern of armyworms, this is especially important for SpexNPV.

There needs, of course, to be adequate knowledge amongst users if they are to successfully apply SpexNPV, which suggests a clear need for training systems and supply chains that can deliver both the product and its supporting knowledge. One option with SpexNPV is to integrate supply into the recently developed network of community-based armyworm forecasting villages (CBAF; Mushobozi et al. 2005). In CBAF, armyworm-specific pheromone traps are distributed to communities, and local farmers are trained to maintain and operate them. This enables local forecasts of armyworm outbreaks to be transmitted to farmers 10-14 days before armyworm outbreaks appear with a high degree of effectiveness (Holt et al. 2006). This CBAF system is now being rolled out in both Kenya and Tanzania and could provide a pathway for promoting the use of SpexNPV. Indeed, by integrating good local forecasting with a supply of more affordable control for armyworm, the sustainability of both forecasting and control should be improved as the benefits for participants are increased. If SpexNPV can be produced on a large scale and at low cost, this could increase the feasibility of implementing a strategic regional control programme for armyworm. Strategic control is based on the concept of the management of early-season outbreaks in the primary outbreak areas of Tanzania and Kenya, specifically to prevent the migration and spread of armyworms to other parts of Africa. It has been argued strongly that strategic control would be economically viable and cost effective, even with conventional synthetic insecticides (Cheke and Tucker 1995). However, fears about the environmental impact of area-wide chemical insecticide application have impeded its adoption as policy and its funding. If a new, completely armyworm-specific, and so safe, selfreplicating BCA, such as SpexNPV, was selected as the primary method of control, it would make strategic control a much more attractive option both to national governments and international development agencies. 


\section{Biocontrol agent safety and ecosystem impacts}

The economic potential for pesticidal plants and other biocontrol agents to protect crops is a key rationale for their use, though other benefits may accrue to human and environmental health. Plant pesticides are relatively safe (see below), despite some popular pesticidal materials in Africa having established short-term negative environmental impacts (Copping and Menn 2000); for example, fish are especially sensitive since artery-rich gills assimilate water-soluble plant toxins easily (Neuwinger 2004). Indeed, many Africans use certain plant materials, like $B$. madagascariensis and $T$. vogelii, to rapidly harvest fish. Some plant compounds that are important in pest control, such as nicotine and rotenoids, also have a relatively high acute mammalian toxicity (Copping and Menn 2000). However, in practice, the acute human health risk of these compounds, as used in pest control, is mitigated by the low concentrations of the active substances typically used in crude preparations. For example, the oral lethal dose of rotenone is reported to be between 300 and $500 \mathrm{mg} / \mathrm{kg}$ in humans (Isman 2008). The maximum concentration of rotenoids in Tephrosia dry leaf is reported to be around $0.1 \%$ by weight (Belmain et al. 2012). If it is assumed all rotenoids are equally as toxic as rotenone (although all are less so), a $70 \mathrm{~kg}$ person would need to consume more than $20 \mathrm{~kg}$ of dry Tephrosia leaf material in one sitting to consume the lowest estimate of the lethal dose. This supports earlier assertions that the risk of acute toxicity during typical exposure to pesticidal plants and specifically Tephrosia at concentrations used by farmers is low (Isman 2008).

Both safety and efficacy can be optimized by standardizing the preparation of pesticidal extracts, but this usually requires chemical analysis. Proper safety testing of candidate pesticidal plants is required before their widespread promotion is undertaken and is already underway for some African plant species (Nyahangare et al. 2012). Plant compounds break down rapidly into harmless residues that have no environmental persistence so minimizing their impact on the wider ecosystem (Stark and Walter 1995); indeed, this can even be their undoing. Much research on neem and rotenone, for example, has been spent developing UV-absorbing adjuvants that increase their longevity in the field (Chen et al. 2009) because they break down too rapidly. When applied on plant surfaces, the half-life of azadirachtin is measured in hours which is very much shorter than most synthetic insecticides (Caboni et al. 2006) and even when used systemically it has a half-life of only between 5 and 12 days (Grimalt et al. 2011). Organic growers accept plant-based pesticides as organic, an increasingly important share of the market. Some plant compounds, such as rotenone, have been widely used by the organic sector; however, their re-registration in the EU has not been supported by a commercial company for economic reasons. European food safety regulations based on the detection of Maximum Residue Levels (MRL) might mean that some plant-derived compounds are unacceptable contaminants on food entering the EU. However, the rapid oxidative and UV breakdown of plant compounds should minimise potential consequences for African farmers who export to Europe, as it is unlikely that toxic plant compounds will be detected as part of MRL screening. Precise knowledge about the natural rates of decomposition for different plant compounds would inform this issue, though this is already known for many, as discussed above (e.g., Caboni et al. 2006). Despite the generally lower risk to farmers and consumers of using pesticidal plants compared to synthetic chemicals (Isman 2006), some plant products may still present hazards. However, these can still be used safely if this risk is correctly managed by adopting evidence-based guidelines on safe use, appropriate equipment, spray intervals and handling, with a view to not only protecting the individual applying or preparing the products and those in the immediate vicinity, but also the potential consumers.

Safety is also a key consideration for microbial biopesticides like SpexNPV. Many of these, such as baculoviruses, fungi and bacteria, are obligate insect pathogens whose high specificity and biodegradability means that they present few or no hazards to users, wildlife or the environment (O.E.C.D 2002; Rosell et al. 2008). Indeed, whilst the very high specificity of SpexNPV means that its use poses little threat to humans, livestock or beneficial insects such as pollinators, it does limit its utility against other crop pests, even those closely related. For a number of taxonomic groups, a substantial body of safety studies exists, quantifying their environmental hazards and risks (Laird et al. 1990; Copping and Menn 2000). For example, a major independent review of the baculoviruses, to which SpexNPV belongs, found no evidence of harmful effects and concluded that their use in pest control raised no issues of safety or negative environmental impact (O.E.C.D 2002). However, for other groups of BCA there is insufficient information and so it is not prudent to assume that all candidate biopesticides are necessarily safe. Robust and evidence-based proof of safety must remain essential before any BCA is accepted for crop protection, and suitable and proportionate safety-screening protocols must exist (Montesina 2003).

\section{Regulation, registration and policy for biological pest control products}

To improve the access of farmers in Africa to the benefits of indigenous pest control agents a range of barriers need to be reduced. The major ones lie less in resolving technical aspects of use, but in improving the regulatory, registration and policy environment. Systems that permit and facilitate the ready marketing of indigenous pest control products are required 
and, while ensuring health and safety processes are upheld, to reduce the restrictive regulations or high regulatory costs. The policy environment in Africa could be changed to better encourage SMEs and community groups to trade in these products if robust sustainable supply chains are to be established. Without the development of an effective trading system for these resources to encourage private sector provision then scaling up the use of indigenous pest control would depend solely on government or NGO programmes of promotion. These, while having short term impacts, rely on external funding and their long term impact and sustainability is not assured. Increasingly the ability to involve the private sector in delivering the benefits of new agricultural research to poor farmers in Africa is seen as the key both to scaling up impact rapidly and ensuring sustainability (Clark et al. 2011).

In many SSA countries, the crop protection registration system was based on that operating in North America and Europe. As such, it was designed specifically for the registration and sale of proprietary chemical pesticides with a single active ingredient, and its protocols did not permit any BCA to be registered. This limitation has now been corrected in some countries, and BCA-enabling registration has been implemented in Kenya (Wabule et al. 2004; Gwynn and Maniania 2010) and in some West African countries (Biocontrol Africa 2012). However, these systems still do not allow for the generic registration of BCA or botanical pesticides. This is complicated further by the multi-component activities of most botanical pesticides, which impedes the ability of SMEs in African countries to develop new BCA based on botanical product lines. This is because toxicology evaluation packages are still mandatory and with complex botanical mixtures these are expensive. Thus, relatively few BCAs have been registered as yet in SSA outside the commercial horticultural hotspots of South Africa and Kenya (Gwynn and Maniania 2010).

In reality, local production and use of pesticidal plant materials for pest control by farmers is not regulated by SSA authorities; however, the commercial development of plantbased pesticides does require regulatory approval. The regulatory hurdles and costs to register and sell BCA products are currently the same as those for synthetic insecticides. Regulations are currently developed in the context of synthetic compounds that involve relatively high costs for registering new products (of between USD 50,000-200,000, in Kenya, for example) and require extensive toxicological safetytesting. Such evaluations could be prohibitively expensive for pesticidal plants whose activities comprise a complex mixture of compounds, often acting synergistically, and analysing such complex mixtures may be beyond the capacity of local research institutes or companies (Isman 2008). The high cost of preparing such a regulatory dossier is prohibitive to small-scale producers wishing to establish local businesses specialising in the trade of pesticidal plant products or other
BCA. In contrast, the regulation of traditional medicines in SSA countries is remarkably "light touch", with no requirements for clinical trials or validation of efficacy and safety, as occurs for modern medicines despite them often being prescribed for use internally (World Health Organisation 2005). Considering traditional medicines may involve ingesting complex concoctions of plant compounds, which often use the same plant species employed as pesticides, there is a clear disjuncture between health and agricultural policy making across SSA. Countries in SSA should look to India, rather than Europe and North America, to learn about developing regulatory frameworks to promote the commercialisation of BCA, especially pesticidal plants. However, ultimately the goal of pesticidal plant research in Africa should be to develop simple, safe and environmentally conscientious protocols for exploitation, regulation and use that can be easily understood and distributed widely by extension services and NGOs to stakeholders in the supply system and end users.

One approach that could be adopted would be to provide small enterprises more favourable procedures in terms of cost and allow the acceptance of safety data and risk analyses from other regulatory zones such as North America, to reduce costs further, a step already proposed in the EU for microbial pesticides (Bailey et al. 2010b). What is clear is that many farmers use these plant materials anyway, but usually without proper validation or information about how to use them safely. Thus, their legitimisation through regulation will enable the distribution of better safety information and improved use, and this should be supported by changes in regulatory policy governing natural products. For example, SSA could adopt regulation models from elsewhere in the world where BCA and pesticidal plants are more widely used commercially. For example, India, China and other south-eastern Asian countries have developed regulatory frameworks that make it much easier to register BCA and plant-based pesticides for commercial sale. In South and Central America there is widespread use of products based on endemic BCA on the presumption that "these naturally occurring, indigenous organisms are much safer than the pesticides they replace" (Jaronski et al. 2003), an approach that attempts to balance the need to protect consumers and farmers without stifling local producers. While the scientific validity of this approach may be questioned, it seems to have produced no significant reports of problems to date.

There are other models of registration in use (Kabuluk et al. 2010), some of which, as in India, permit staged registration of BCA that are already known to be safe, such as BVs, without the need for upfront submission of expensive registration dossiers, thereby reducing costs and facilitating biopesticide registration by local companies (Rabindra and Grzywacz 2010). Similarly there are moves within the EU by individual countries to lower costs and facilitate the registration of microbial pesticides (Chandler et al. 2008). One model is the 
adoption of qualified presumption of safety (QPS), a status conferred upon a specific taxonomic group of microbial pesticides (usually a species but sometimes a genus or strain) by the European Food Standards Agency, once adequate evidence has been accumulated that its use poses no risks (Ehlers 2011). Once a taxonomic group has QPS status, no further risk assessments are required of products submitted for registration (Cuddiford and Kabaluk 2010). The USA has a similar approach with its generally regarded as safe (GRAS) system. A similar approach applied to plants might be one suitable way forward.

\section{Economics and business models for biocontrol agents}

Translating research initiatives on BCA in Africa into products for farmers has been a significant problem with only limited success (Cherry and Gwynn 2007). While there has been much research into BCA, and classical biological control has produced some highly successful and beneficial programmes (Neuenschwander et al. 2003), few endemic BCA have been developed into crop protection products for Africa (Grzywacz et al. 2009). This, in part, reflects a research agenda driven more by perceived needs and academic imperatives rather than an effective BCA commercial development model (Lisansky 1997). It is also a consequence of donor funding models that paid for basic research but, in the past at least, devoted few or no resources to post-research product development or research impact (Grzywacz et al. 2009). This is at last showing signs of change, with donors such as the UK's Department for International Development (DFID) funding programmes such as Research Into Use that are specifically aimed at turning previously-funded research into knowledge and products that poor farmers in Africa can access and use (Clark et al. 2011). Indeed, this DFID RIU programme has recently funded the building of a state-of-theart plant for SpexNPV processing in Tanzania. Another important sea-change in donor support for development is the growing recognition that, if agriculture in Africa is to be transformed out of its low productivity ghetto, there is a need to bring private sector skills, resources and investment into the process of turning research into development impact (Hall et al. 2010).

Developing viable and sustainable commercial businesses, based on harvesting of wild plants and other BCA, for pesticides is a relatively novel activity for SMEs in Africa and likely to be a challenge, as there is little specific experience to build on. One approach would be to learn from other "wild harvesting" businesses that have already been developed as commercial businesses such as those exploiting non-timber forest products (NTFPs). There is a body of research studying the commercialisation of NTFPs which has identified that sustainable management of such resources and improving local livelihoods needs careful planning and implementation if biodiversity is to be conserved and damaging over exploitation avoided (Belcher and Schreckenberg 2007). The legal requirements for trading and local governance need to be appropriate to facilitate establishing a viable trading system and there are complex social, economic and environmental aspects that need to be factored in if commercialisation is to be viable and sustainable (Marshall et al. 2006). Thus, careful research into identifying a suitable commercialisation model for BCA and pesticidal plants and identifying the components of an enabling regulatory environment are priorities on a par with research on any of the ecological or biological aspects of any system.

Research on many pesticidal plants is still needed to better understand the mechanisms of propagation and how harvesting and preparation can be improved to better conserve, or indeed improve, ecosystems and these valuable ecosystem resources. This knowledge will facilitate the reliability of supply and uptake of pesticidal plants, as well as potentially safeguarding or augmenting current ecosystem services. Scientists also need to engage policy makers to conserve wild habitats and to reduce the potential negative impacts of commercialisation. Governments in SSA can encourage use of plants in pest control but need to understand that this requires support for conservation, propagation and commercialisation, as already occurs for the commercialisation of some herbal remedies (Sarasan et al. 2011). Encouraging African farmers to replicate the successes of growing and marketing pyrethrum could be achieved for many other African pesticidal plant species. With some simple regulatory changes, farmers currently growing species such as T. vogelii could sell their product to other farmers; say in peri-urban areas where agricultural land is too limited to produce one's own. Such a policy change would reduce SSA's reliance on the import of commercial synthetic pesticides, reduce collection pressure on wild plant resources, increase farm incomes and increase demand for more environmentally-sustainable, safe and reliable pest control.

Countries in SSA should perhaps look to India and China, as opposed to Europe and North America, on how to successfully develop their regulatory frameworks to promote the commercialisation of BCA, especially pesticidal plants. Improving our knowledge of variation in efficacy, conservation and regulation remain the biggest hurdles for pesticidal plants in SSA.

\section{Conclusions}

The cases of SpexNPV and botanical pesticides provide examples of modern science and traditional knowledge combining to produce crop protection solutions that potentially could be more appropriate and affordable for poor farmers in Africa 
who are currently unable to access almost any effective crop protection. However, the sustainable harvesting and management of these pesticidal ecosystems services will require underpinning technical research to identify appropriate harvesting systems that can supply the quantity and quality needed to meet the pest control needs of farmers on both the scale required and at the appropriate times in the cropping cycle. Addressing these issues within a broader ES framework could add value to these resources by recognising the role that many of them play in the provision of other ecosystem services and goods, such as improved soil and water quality, carbon sequestration and wider cultural benefits. The successful exploitation of these ecosystem services will itself also require significant policy changes as well as appropriate research to identify models of commercialisation more suited to supplying subsistence agriculture in SSA than the existing agri-input production, regulation and marketing systems.

Acknowledgments The authors gratefully acknowledge the following for funding the research that forms the foundation for this paper: the U.K. Department for International Development, the U.K. Biotechnology and Biological Sciences Research Council, Africa Caribbean and Pacific Science and Technology Programme of the European Union and the McKnight Foundation. This paper is an output from a Royal Society Leverhulme Trust Senior Research Fellowship awarded to KW. We are grateful to the Ecosystem Services for Poverty Alleviation (ESPA) programme for stimulating us to write this paper, and to several reviewers for helping us to improve it.

Open Access This article is distributed under the terms of the Creative Commons Attribution License which permits any use, distribution, and reproduction in any medium, provided the original author(s) and the source are credited.

\section{References}

Abate, T., van Huis, A., \& Ampofo, J. K. O. (2000). Pest management strategies in traditional agriculture: an African perspective. Annual Review of Entomology, 45, 639-655.

ACP Secretariat (2010) http://www.acp-st.eu/content/african-drylandalliance-pesticidal-plant-technologies-network-optimising-andpromoting-use- . Accessed 9 April 2013.

Anon (2012) Ecosystem services for poverty alleviation program http:// www.espa.ac.uk/. Accessed 04 April 2013.

Armes, N. J., Jadhav, D. R., \& De Souza, K. R. (1996). A survey of insecticide resistance in Helicoverpa armigera in the Indian sub-continent. Bulletin of Entomological Research, 86, 499-514.

Bailey, K. L., Boyetchko, S. M., \& Langle, T. (2010a). Social and economic drivers shaping the future of biological control: a Canadian perspective on the factors affecting the development and use of microbial biopesticides. Biological Control, $52,221-229$.

Bailey, A., Chandler, D., Grant, W. P., Greaves, J., Prince, G., \& Tatchell, M. (2010b). Biopesticides pest management \& regulation. Wallingford: $\mathrm{CAB}$ International.

Belcher, B., \& Schreckenberg, K. (2007). Commercialisation of nontimber forest products: a reality check. Development Policy Review, 25, 355-377.
Belmain, S. R., \& Stevenson, P. C. (2001). Ethnobotanicals in Ghana: reviving and modernising an age-old practise. Pesticide Outlook, 6 , 233-238.

Belmain, S. R., Amoah, B. A., Nyirenda, S. P., Kamanula, J. F., \& Stevenson, P. C. (2012). Highly variable insect control efficacy of Tephrosia vogelii chemotypes. Journal of Agricultural and Food Chemistry, 60, 1055-1066.

Bianchi, F. J. J. A., Booij, C. J. H., \& Tscharntke, T. (2006). Sustainable pest regulation in agricultural landscapes: a review on landscape composition, biodiversity and natural pest control. Proceedings of the Royal Society, Series B., 273, 1715-1727.

Bielza, P., Denholm, I., Sterk, G., Leadbeater, A., Leonard, P., \& Jørgensen, L. N. (2008). Declaration of Ljubljana - the impact of a declining European pesticide portfolio on resistance management. Outlooks on Pest Management, 19, 246-248.

Biocontrol Africa. (2012). Biopesticides the state of play. http:// biocontrolafrica.com/default.htm. Accessed 09 April 2013.

Brown, E. S., \& Swaine, G. (1965). Virus disease of the African armyworm, Spodoptera exempta (Walker). Bulletin of Entomological Research, 56, 671-684.

Broza, M., Brownbridge, M., Shavit, A., Maniana, N. K., Sneh, B. (1999). Control of African armyworm Spodoptera exempta and the Egyptian cotton leafworm S. littoralis with Bacillus thuringiensis var aizawai, neem and a combination of both control agents. Abstract. International symposium on Biological control agents in Crop and Animal protection 24-28 th August 1999. University of Swansea.

Burges, H. D., \& Jones, K. A. (1998). Technology of formulation and Application. In H. D. Burges (Ed.), Formulation of Microbial biopesticides (pp. 1-5). Dordrecht: Kluwer Academic Publishers.

Burkill, H. M. (1995). The useful plants of west tropical Africa (Vol. 3). Kew: Royal Botanic Gardens.

Caboni, P., Sarais, G., Angioni, A., Garcia, A. J., Lai, D. F., et al. (2006). Residues and persistence of neem formulations on strawberry after field treatment. Journal of Agricultural and Food Chemistry, 54, 10026-10032.

Chandler, D., Davidson, G., Grant, W. P., Greaves, J., \& Thatchell, G. M. (2008). Microbial biopesticides for integrated crop management: an assessment of environmental and regulatory sustainability. Trends in Food Science \& Technology, 19, 275-283.

Cheke, R. A., \& Tucker, M. R. (1995). An evaluation of potential economic returns from the strategic control approach to the management of African Armyworm Spodoptera exempta (Lepidoptera; Noctuidae) populations in Eastern Africa. Crop Protection, 14, 91-103.

Chen, X. J., Xu, H. H., Yang, W., \& Liu, S. Z. (2009). Research on the effect of photoprotectants on photostabilization of rotenone. Journal of Photochemistry and Photobiology B-Biology, 95, 93-100.

Cherry, A. J. (1992). Cross infectivity of Spodoptera exempta nuclear polyhedrosis virus (SeNPV) and the infectivity of foreign viruses in S. exempta. Technical project completion report project A0047. Chatham: Natural Resources Institute, University of Greenwich.

Cherry, A. J., Parnell, M., Grzywacz, D., Brown, M., \& Jones, K. A. (1997). The optimization of in vivo nuclear polyhedrosis virus production of Spodoptera exempta (Walker) and Spodoptera exigua (Hubner). Journal of Invertebrate Pathology, 70, 50-58.

Cherry, A. J., \& Gwynn, R. L. (2007). Perspective on the development of biocontrol in Africa. Biocontrol Science and Technology, 17, 665-676.

Clark, N., Frost, A., Maudlin, I., Seward, P., Wainwright, H., \& Ward, A. (2011). Putting research into use: a market failure approach. International Journal of Technology Management \& Sustainable Development, 10(3), 185-200. doi:10.1386/tmsd.10.3.185 1.

Copping, L. G. (2009). Manual of biocontrol agents (4th ed.). Alton: British Crop Protection Council.

Copping, L. G., \& Menn, J. J. (2000). Biopesticides: a review of their action application and efficacy. Pesticide Management Science, 56, 651-676.

Crop Life International (2012). Obsolete stock management. http://www. croplife.org/obsolete_stocks. Accessed 9 April 2013. 
Cuddiford,V. \& Kabaluk, T. (2010). Alternative regulatory models for microbial pesticides. In Kabuluk, T., Svircev, A., Goettel, M., Woo, S.G. (Eds.). Use and Regulation of Microbial Pesticides in Representative Jurisdictions Worldwide (pp94-98), IOBC Global.

Day, R. K., Haggis, M. J., Odiyo, P. O., Mallya, G., Norton, G. A., \& Mumford, J. D. (1996). WormBase: A data management and information system for forecasting Spodoptera exempta (Lepidoptera: Noctuidae) in eastern Africa. Journal of Economic Entomology, 89, 1-10.

Deng, A. L., Ogendo, J. O., Owuor, G., Bett, P. K., Omolo, E. O., Mugisha-Kamatenesi, M., \& Mihale, J. M. (2009). Factors determining the use of botanical insect pest control methods by smallholder farmers in the Lake Victoria basin, Kenya. African Journal of Environmental Science and Technology, 3, 108-115.

Dinham, B. (2003). Growing vegetables in developing countries for local urban populations and export markets: problems confronting smallscale producers. Pest Management Science, 59, 575-582.

Dubey, N. K. (Ed.). (2011). Natural products in plant pest management. Wallingford: CAB International.

Douthwaite, B., Langewald, J., \& Harris, J. (2001). Development and commercialization of the green muscle biopesticide. Ibaden: International Institute of Tropical Agriculture.

Ehlers, R.-U. (2011). Regulation of biological control agents . Dordrecht: Springer.

Evenson, R. E., \& Gollin, D. (2003). Assessing the impact of the green revolution 1960 to 2000. Science, 300, 758-762.

Fisk, T., Cooper, J., \& Wright, D. J. (1993). Control of Spodoptera spp. Using ULV formulations of Acylurea insect growth regulator, Flufenoxuron: field studies with Spodoptera exempta and effect of toxicant concentration on contact activity. Pesticide Science, 39, 79-83.

Graham, R. I., Grzywacz, D., Mushobozi, W. L., \& Wilson, K. (2012). Wolbachia in a major African crop pest increases susceptibility to viral disease rather than protects. Ecology Letters, 15(9), 993-1000.

Grimalt, S., Thompson, D., Chartrand, D., McFarlane, J., Helson, B., Lyons, B., et al. (2011). Foliar residue dynamics of azadirachtins following direct stem injection into white and green ash trees for control of emerald ash borer. Pest Management Science, 67, 1277-1284.

Grzywacz, D., Mushobozi, W., Parnell, M., Jolliffe, F., \& Wilson, K. (2008). The evaluation of Spodoptera exempta nucleopolyhedrovirus (SpexNPV) for the field control of African armyworm (Spodoptera exempta) in Tanzania. Crop Protection, 27, 17-24.

Grzywacz, D., Cherry, A. C., \& Gwynn, R. (2009). Biological pesticides for Africa: why has so little of the research undertaken to date led to new products to help Africa's poor? Pesticide Outlook, 20, 77-81.

Gwynn R., \& Maniania, J.K. (2010). Africa with special reference to Kenya. In T. Kabuluk, A. Svircev, M. Goettel, \& S.G. Woo (Eds.) Use and Regulation of Microbial Pesticides in Representative Jurisdictions Worldwide (pp12-17), IOBC Global.

Hall, A., Clark, N., \& Frost, A. (2010). Bottom up, bottom-line: development relevant enterprises in East Africa and their significance for agricultural innovation (Research into Use Discussion paper 02). Alyesford: Natural Resources International.

Harnischfeger, G. (2000). Proposed guidelines for commercial collection of medicinal plant material. Journal of Herbs, Spices and Medicinal Plants, 7, 43-50.

Hofs, J.-L., Fok, M., \& Vaissayre, M. (2006). Impact of Bt cotton adoption on pesticide use by smallholders: A 2-year survey in Makhatini Flats (South Africa). Crop Protection, 25, 948-988.

Holt, J., Mushobozi, W., Day, R. K., Knight, J. D., Kimani, M., N'juki, J., $\&$ Musebe, R. (2006). A simple Bayesian network to interpret the accuracy of armyworm outbreak forecasts. Annals of Applied Biology, 148, 141-146.

Isman, M. B. (2006). Botanical insecticides, deterrents, and repellents in modern agriculture and an increasingly regulated world. Annual Review of Entomology, 51, 45-66.

Isman, M. B. (2008). Botanical insecticides: for richer, for poorer. Pest Management Science, 64, 8-11.
Jaronski, S. T., Goettel, M. S., \& Lomer, C. J. (2003). Regulatory requirements for ecotoxicological assessments of microbial insecticides-how relevant are they? In H. M. T. Hokkanen \& A. E. Hajeck (Eds.), Environmental impacts of microbial insecticides: Need and methods for risk. Dordrecht: Kluwer Academic Publishers.

Jayasekera, T., Stevenson, P. C., Belmain, S. R., \& Hall, D. R. (2002). Methylsalicylate isomers in the roots of Securidaca longepedunculata. Journal of Mass Spectrometry, 37, 577-580.

Jayasekera, T., Stevenson, P. C., Hall, D. R., \& Belmain, S. R. (2005). effect Of volatile constituents from Securidaca longepedunculata on stored grain insect pests. Journal of Chemical Ecology, 31, 303-313.

Jenkins, N., \& Grzywacz, D. (2000). Quality control - assurance of product performance. Biocontrol Science and Technology, 10, 753-777.

Kabuluk, T., Svircev, A., Goettel, M., Woo, S.G. (2010). Use and regulation of microbial pesticides in representative jurisdictions worldwide, IOBC Global, 108pp

Kamanula, J., Sileshi, G. W., Belmain, S. R., Sola, P., Mvumi, B. M., Nyirenda, G. K. C., et al. (2011). Farmers' Insect Pest management practices and pesticidal plant use for protection of stored maize and beans in Southern Africa. International Journal of Pest Management, 57, 41-49.

Khan, Z. R., Midega, C. A. O., Bruce, T. J. A., Hooper, A. M., \& Pickett, J. A. (2010). Exploiting phytochemicals for developing a 'pushpull' crop protection strategy for cereal farmers in Africa. Journal of Experimental Botany, 61, 4185-4196.

Lacey, L., Frutos, R., Kaya, H. K., \& Vail, P. (2001). Insect pathogens as biocontrol agents: do they have a future? Biological Control, 21, 230-248.

Laird, M., Lacey, L. A., \& Davidson, E. W. (1990). Safety of microbial pesticides. Boca Raton: CRC Press.

Lenne, J. (2000). Pests and poverty: the continuing need for crop protection research. Outlook on Agriculture, 4, 235-250.

Lisansky, S. (1997). Microbial biopesticides. In microbial insecticides: Novelty or necessity? (pp. 3-10), Farnham, British Crop Protection Council Proceedings/Monograph Series No. 68.

Mace, G. M., Norris, K., \& Fitter, A. H. (2012). Biodiversity and ecosystem services: a multilayered relationship. Trends in Ecology and Evolution, 1, 19-26.

Mafongoya, P. L., \& Kuntashula, E. (2005). Participatory evaluation of Tephrosia species and provenances for soil fertility improvement and other uses using farmer criteria in eastern Zambia. Experimental Agriculture, 41, 69-80.

Marshall, E., Schreckenberg, K., \& Newton, A. C. (2006). Commercialization of non-timber forest products: Factors influencing success. Lessons learned from Mexico and Bolivia and policy implications for decision-makers. Cambridge: UNEP World Conservation Monitoring Centre.

Medungno, C. C., Feraz, J. M. G., Maia, A.-d. H. N., \& Fritas, C. C. L. (1997). Evaluation of a wettable powder formulation for the nuclear polyhedrosis virus of Anticarsia gemmatalis (Lep.: Noctuidae). Pesticide Science, 51, 153-156.

Millennium Ecosystem Assessment. (2005). Ecosystems and human well-being: synthesis. Washington: DC, Island Press.

Moore, S. D. (2002). Entomopathogens and microbial control of citrus pests in South Africa: a review. South African Fruit Journal, $1,30-32$.

Montesina, E. (2003). Development, registration and commercialization of microbial pesticides for plant protection. International Microbiology, 6, 245-252.

Moscardi, F. (1999). Assessment of the application of baculoviruses for the control of Lepidoptera. Annual Review of Entomology, 44, 257 289.

Moscardi, F. (2007). Development and use of the nucleopolyhedrovirus of the velvet bean caterpillar in soybeans. In C. Vincet, M. Goettel, 
\& M. S. Lazarovits (Eds.), Biological control: a global perspective (pp. 344-353). Wallingford: CAB Publishing.

Mushobozi, W. L., Grzywacz, D., Musebe, R., Kimani, M., \& Wilson, K. (2005). New approaches to improve the livelihoods of poor farmers and pastoralists in Tanzania through monitoring and control of African armyworm, Spodoptera exempta. Aspects of Applied Biology, 75, 37-35.

Neuenschwander, P., Borgemeister, C., \& Langwald, J. (2003). Biological control in IPM systems in Africa. CABI International: Wallinford.

Neuwinger, H. D. (2004). Plants used for poison fishing in tropical Africa. Toxicon, 44, 417-430.

Nyahangare, E. T., Hove, T., Mvumi, B. M., Hamudikuwanda, H., Belmain, S. R., Madzimure, J., \& Stevenson, P. C. (2012). Acute mammalian toxicity of four pesticidal plants. Journal of Medicinal Plants Research, 6, 2674-2680.

N'juki, J., Mushobozi, W., \& Day, R. (2004). Improving armyworm forecasting and control in anzania: a socio-economic survey. Nairobi: CABI Africa Regional Centre.

Nyirenda S.P.N. (2013). Botanical pesticides: optimized pest management with botanical pesticides on legume cropping systems in Malawi and Tanzania. McKnight Collaborative Crop Research Programme. http://mcknight.ccrp.cornell.edu/projects/saf_cop/ SAF_09-297/09-297_project.html Accessed August 2013.

Nyirenda, S. P. N., Sileshi, G., Belmain, S. R., Kamanula, J. F., Mvumi, B., Sola, P., et al. (2011). Farmers' ethno-ecological knowledge of vegetable pests and their management using pesticidal plants in Northern Malawi and Eastern Zambia. African Journal of Agricultural Research, 6, 1525-1537.

Odindo, M. O. (1983). Epizootiological observations on a nuclear polyhedrosis of the African armyworm Spodoptera exempta (Walk.). Insect Science and its Application, 4, 291-298.

Odindo, M. O. (1981). Dosage-mortality and time-mortality responses of the armyworm Spodoptera exempta to a nuclear polyhedrosis virus. Journal of Invertebrate Pathology, 38, 251-255.

O.E.C.D. (2002). Consensus document on information used in assessment of environmental applications involving baculoviruses. Series on harmonisation of regulatory oversight in biotechnology No. 20. $\mathrm{ENV} / \mathrm{JM} / \mathrm{MONO}(2002) 1$,

Oerke, E. C., \& Dehne, H. W. (2004). Safeguarding production losses in major crops and role of crop protection. Crop Protection, 23, 275285.

Rabindra, R.J., \& Grzywacz, D. (2010). India. In T. Kabuluk, A, Svircev, M, Goettel, \& S.G. Woo (Eds) Use and regulation of microbial pesticides in representative jurisdictions worldwide (pp12-17), IOBC Global.

Romeis, J., Shelton, A M., Kennedy, G.C. (2008) Integration of insect resistant genetically modified Crops within IPM programs. Progress in Biological Control Volume 5, Springer, $441 \mathrm{pp}$.

Rose, D. J. W., Dewhurst, C. F., \& Page, W. W. (2000). The African armyworm handbook. Chatham: Natural Resources Institute, University of Greenwich.

Rosell, G., Quero, C., Coll, J., \& Guerrero, A. (2008). Biorational insecticides in pest management. Journal of Pesticide Science, 33, 103-121.

Sajeev, T. V., Sudheendrakumar, V. V., Biji, C. P., Helen, M. H., \& Varma, R. V. (2005). Economics of HpNPV production using field collected and laboratory reared Hyblea puera (Crammer) (Lepidoptera : Hyblaeidae). Journal of Biocontrol, 19, 193-196.

Sarasan, V., Kite, G. C., Sileshi, G. W., \& Stevenson, P. C. (2011). The application of Phytochemistry and in vitro tools to the sustainable utilisation of medicinal and pesticidal plants for income generation and poverty alleviation. Plant Cell Reports, 30, 1163-1172.

Scott, P. J. (1991). A general review of the evidence on the economic importance of the African Armyworm. Nairobi: Desert Locust Control Organisation East Africa, Technical Report 100.

Shackleton, C. M., Guthrie, G., \& Main, R. (2005). Estimating the potential role of commercial over-harvesting in resource viability: A case study of five useful tree species in South Africa. Land Degradation \& Development, 16, 273-286.

Shelton, A. M. (2004). Management of the diamondback moth: déjà vu all over again? In N.M. Endersby and P. Ridland, (Eds) The management of diamond back moth and other crucifer pests. Proceedings 4th International Workshop on Diamond Back Moth, (pp. 3-8), Melbourne.

Smit, P. H. (1997). Insect pathogens; their suitability as biopesticides. In: Microbial insecticides: novelty or necessity? (pp 21-29), Farnham, British Crop Protection Council, Proceedings/Monograph Series No. 68 .

Ssenyonjo, J. \& Kyaterekera, D. (2009). Application of organic pesticide technologies for improved agriculture and rural livelihoods in Uganda. In: Agricultural Innovations for sustainable development. (pp 65-70), Nairobi, Kenya. African Technology Policy Studies Network

Stark, J. D., \& Walter, J. F. (1995). Persistence of azadirachtin A and B in soil: Effects of temperature and microbial activity. Journal of Environmental Science and Health. Part. B, 30, 685-698.

Stevenson, P. C., Kite, G. C., Lewis, G. P., Nyrienda, S. P., Forest, F., Belmain, S. R., et al. (2012). Distinct chemotypes of Tephrosia vogelii: implications for insect pest control and soil enrichment. Phytochemistry, 78, 135-146.

Stevenson, P. C., Nyirenda, S. P., Sileshi, G., Kamanula, J. F., Mvumi, B. M., Sola, P., et al. (2010). Southern African Pesticidal Plants (SAPP) Project (Caesalpinioid woodlands of Southern Africa: optimising the use of pesticidal plants). Chatham: Final Technical Report, Natural Resources Institute, University of Greenwich.

Stevenson, P. C., Jayasekera, T. K., Belmain, S. R., \& Veitch, N. C. (2009). Bisdesmosidic saponins from Securidaca longepedunculata (Polygalaceae) with deterrent and toxic properties to Coleapteran storage pests. Journal of Agricultural and Food Chemistry, 57, $8860-8867$.

Stoll, G. (2000). Natural plant protection in the tropics (2nd ed.). Weikersheim: Magraf Publishers.

Tanzubil, P. B., \& McCaffery, A. R. (1990). Effects of azadarachtin and aqueous neem seed extracts on survival, growth and development of the African Armyworm Spodoptera exempta. Crop Protection, 9, 383-386.

Thakore, Y. (2006). The Biopesticides market for global agricultural use. Industrial Biotechnology, 2, 194-208.

Thokozani, B. L. K., Zulu, D., Sileshi, G. W., Teklehaimanot, Z., Gondwe, D. S. B., Sarasan, V., et al. (2011). Seed germination and in vitro regeneration of the pan African medicinal and pesticidal plant Bobgunnia madagascariensis. African Journal of Biotechnology, 10, 5959-5966.

USAID (2008) Emergency Transboundary Outbreak Pest (ETOP) situation update for May, 2008 with a forecast till July. http://www.usaid. gov/our_work/humanitarian_assistance/disaster_assistance/locust/ factsheets/fy2008/ETOP_update_may_08.pdf. Accessed 7 February 2012.

USAID (2013) Emergency Transboundary Outbreak Pest (ETOP) situation report for December with a forecast till mid-February, 2013. http://transition.usaid.gov/our work/humanitarian assistance/ disaster_assistance/locust/factsheets/fy2013/ETOP_update_ december 2012.pdf. Accessed 11 February 2013.

Wabule, M. N., Ngaruiya, P. N., Kimmins, F. K., \& Silverside, P. (Eds.). (2004). Registration for biocontrol agents in Kenya. Proceedings of the PCPB/KARI/DFID CPP Workshop, Nakuru, Kenya 14-16 May 2003. Alyesford: Natural Resources International.

World Bank (2013) Obsolete Pesticide Stockpiles: An Unwanted Legacy of the African Landscape. http://www.worldbank.org/en/news/ feature/2013/08/05/obsolete-pesticide-stockpiles-an-unwantedlegacy-of-the-african-landscape Accessed 15 August 2013.

World Development Report. (2008). Agriculture for Development. The 
World Blank, Washington DC, USA. http://siteresources.worldbank. org/INTWDR2008/Resources/2795087-1192112387976/WDR08 04 ch02.pdf. Accessed15 February 2011.

World Health Organisation (2005). National policy on traditional medicine and regulation of herbal medicines: report of a WHO global survey. World Heath Organisation ISBN 924159323 7. 156 pp. http://apps.who.int/medicinedocs/en/d/Js7916e/. Accessed 9 April 2013.

Zulu, D., Thokozani, B. L. K., Sileshi, G. W., Teklehaimanot, Z., Gondwe, D. S. B., Sarasan, V., et al. (2011). Towards successful propagation of the African medicinal and pesticidal plant Securidaca longependunculata. African Journal of Biotechnology, 10, 59885992.

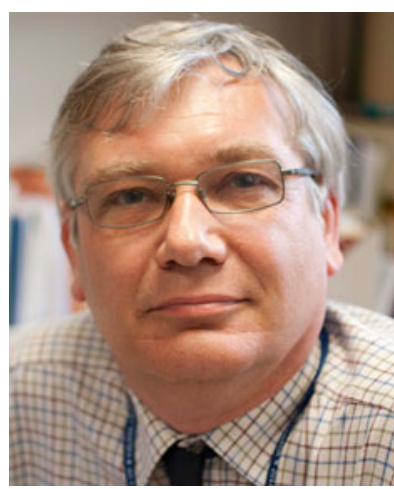

David Grzywacz is an expert in biological control of insect pests with pathogens. His research focus is on developing new pest control systems using insect viruses in developing countries. His research has covered all aspects of biopesticides from the initial isolation and evaluation through to mass production and advice on regulation. He has worked with research institutes, universities, SMEs and private sector clients in Africa, Asia and South America

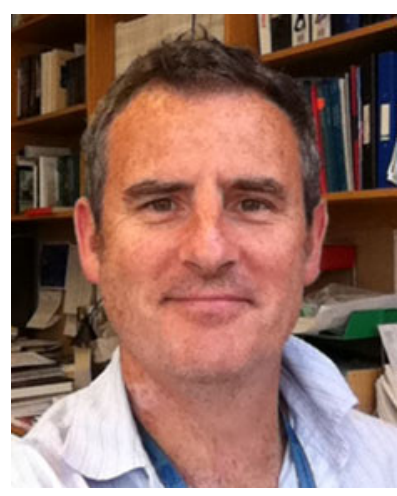

Professor Phil Stevenson has twenty years' experience of isolating, identifying and elucidating structures of plant chemicals and determining their biological activities. Particular interests include plant pesticides in resource-poor farming in Africa, resistance mechanisms to insects and diseases in crops e.g., sweet potato, groundnuts, chickpea, rice and the chemical ecology of pollination. Current funding sources include National Science Foundation (USA), BBSRC, Science Foundation of Ireland, European Union (ACP S\&T) and McKnight Foundation.

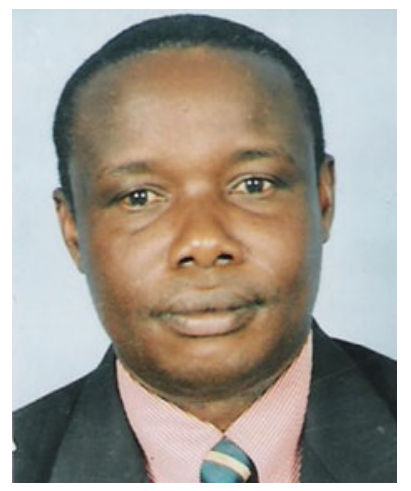

Wilfred Mushobozi is Managing Director of Eco Agri Consultancy services Ltd, a company dedicated to deliver technologies that will reduce or eliminate constraints to crop productivity caused by pest organisms, diseases, or environmental stress. For more than 20 years he has been active in migratory pest forecasting and research on the biological control of African armyworm, including the development of formulation, production and quality control systems for armyworm nucleopolyhedrovirus in Tanzania.

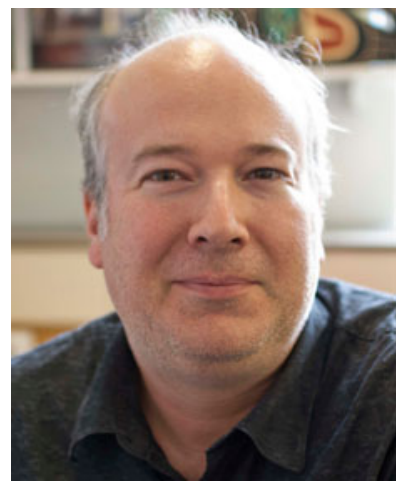

Steve Belmain carries out his research on vertebrate and in invertebrate pest management in the Agriculture Health and Environment Department of the Natural Resources Institute. He leads many large multi-national and multi-disciplinary research projects with funding won from a wide range of donors including the UK's Department for International Development, the European Commission RTD Framework and Europe Aid EDF programmes, UNDP, WHO and the McKnight Foundation. His areas of research span across small mammals, zoonoses and the chemical and behavioural ecology of insects, particularly the optimisation of pesticidal plants for sustainable agroecological intensification.

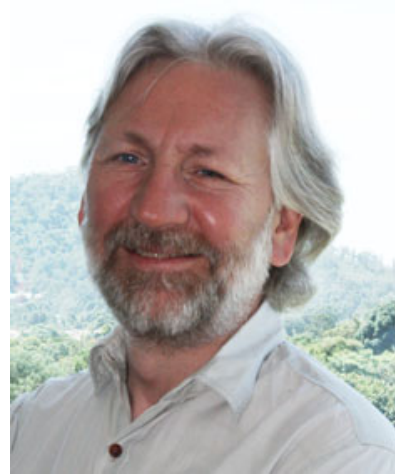

Ken Wilson is a Professor of evolutionary ecology in the Environment Centre at Lancaster University. $\mathrm{He}$ is interested in the biological interactions between insect crop pests and their natural enemies, especially baculoviruses and bacteria, and how these microbes can be developed as biological control agents. $\mathrm{He}$ has been conducting research in Africa for nearly 25 years 